\title{
Um dos budismos possíveis - Uma interpretação laica de alguns de seus conceitos básicos *
}

\author{
Jorge Vulibrun ${ }^{l}$ \\ Universidade Federal de Santa Catarina
}

Este trabalho faz uma apresentação dos conceitos básicos do budismo, desprovidos, dentro do possível, das nuances próprias de cada cultura onde ele se instalou. Para tanto, nas suas interpretações são destacadas as raízes sânscritas de cada um desses conceitos, conduzindo a uma interpretação "laica" desse pensamento. São destacadas também algumas oposições, tais como instante-momento, renascimento-reencarnação, processoobjeto, identidade-continuidade, bem como "estar sendo" versus "ser".

Palavras-chave: Budismo "Estar sendo" e "ser" - Momento presente - "Processos" e "objetos"

This paper is a presentation of the basic concepts of Buddhism, stripped, to the extent possible, of the nuances of each culture where it was installed. To do so, in their interpretations are highlighted the Sanskrit roots of each of these concepts, leading to a "secular" interpretation of that thought. Some oppositions are also highlighted, such as instant-moment, rebirthreincarnation, process-object, identity-continuity, and "being" versus "to be".

Keywords: Buddhism - "Being" vs. "to be" - Present moment - "Processes" vs. "objects"

\section{Introdução}

\begin{abstract}
Buda perguntou: "Qual é a duração da vida?" Um discípulo respondeu: "Um inspirar e um expirar". Buda completou: "Tens avançado no caminho da compreensão".
\end{abstract}

\footnotetext{
Dara percorrer um caminho dentro de uma nova cidade é necessário, inicialmente, um mapa para nos guiar e orientar. Só depois de ter percorrido esse caminho inúmeras vezes poderemos prescindir desse mapa e dirigir nossa atenção tanto aos prédios que o beiram quanto às árvores e flores que o adornam e que formam o caminho verdadeiro, que não é aquele desenhado no mapa.

" One of the possible Buddhisms - A secular interpretation of some of its basic concepts.

${ }^{1}$ Endereço para correspondências: Rua Lacerda Coutinho, 148, Centro, Florianópolis/SC 88015-030 (jorgevul@uol.com.br)
} 
Apesar de o budismo pregar a diminuição do racional e da intelectualização e sua substituição pela intuição, é inevitável começarmos com um mapa.

Como é tão comum no Oriente, o budismo iniciou-se como uma escola filosófica e acabou se transformando numa religião (ou, mais propriamente, em várias religiões: o Vajrayana tibetano, o Hinayana do Sudeste da Ásia ou o Terra Pura japonês, são exemplos da diversidade que o budismo religioso adotou). Também nisso, o Oriente se apresenta como oposto ao Ocidente, onde as religiões tendem a se converter em filosofias. Os conceitos básicos budistas sofreram, à medida que o budismo se espalhava pela Ásia, uma profunda elaboração desde que começaram a ser formulados, no século VI a.C. Acompanhando as diferentes formas culturais onde o budismo se instalou, eles incorporaram nuances mais ou menos religiosas, esotéricas ou filosóficas. Como esses conceitos podem ser equiparados às placas de uma estrada, que alertam e destacam diversos pontos dela, e necessário esclarecer que eles são utilizados neste texto baseados, fundamentalmente, nas suas raízes sânscritas ${ }^{2}$, num intento de apresentá-los de uma forma mais próxima ao seu uso inicial, ou seja, desprovidos, ao máximo, de posteriores acréscimos culturais.

Eis aqui um mapa de um dos budismos possíveis, que, neste caso, é fundamentalmente laico.

\section{A estrada do budismo}

O ponto fundamental do budismo é que as dificuldades pelas quais passamos em nossa vida são decorrentes de pontos de vista equivocados, sendo eles resultantes, por sua vez, de mecanismos automáticos (e, portanto, não questionados) do nosso processo cognitivo.

Na continuação, avaliaremos os principais pontos questionados pelo budismo.

\section{Um mundo de processos ou o processo do mundo?}

O budismo compartilha com as principais linhas do pensamento oriental a visão de que o mundo é formado por uma miríade de processos ${ }^{3}$ interdependentes (o que em chinês é chamado de 萬物 wan wu, as dez mil coisas ou processos),

\footnotetext{
${ }^{2}$ Fontes principais das raízes sânscritas: WIKIPEDIA, consultadas em Outubro/2010.

${ }^{3}$ Processo: "Ação continuada, realização contínua e prolongada de alguma atividade; seguimento, curso, decurso. Sequencia contínua de fatos ou operações que apresentam certa unidade ou que se reproduzem com certa regularidade; andamento, desenvolvimento, marcha". Utilizada como alternativa a "coisa", que se restringe ao material e aos objetos, e a "fenômeno", que se refere àquilo que nos aparece, mas que fica demasiadamente vinculado à nossa percepção. Em chinês, 物 wù "coisa", inclui os objetos materiais e imateriais, os animais e os humanos, por isso é mais bem traduzida por "processo".
} 
cada um deles seguindo seus princípios imanentes, ou seja, aqueles que lhe são próprios. Estes processos estão fluindo permanentemente, interagindo entre si, numa sucessão interminável que caracteriza o processo que engloba tudo o que existe, existiu ou existirá - deuses, inclusive ${ }^{4}$.

Portanto, a visão oriental não concebe o mundo como formado por inúmeros objetos, como faz a ocidental. Processos tendem naturalmente a uma interação entre eles, enquanto que objetos tendem naturalmente à diferenciação. Assim, os pensadores orientais priorizavam a "continuidade", enquanto que o Ocidente prioriza a "identidade". Dentro de um contexto que prioriza os processos, o conceito de "identidade" fica, no mínimo, comprometido5: esta mesa é uma mesa e aquela mesa também é uma mesa e também tem quatro pés, mas uma é de imbuia e a outra de pinho, uma pode harmonizar um determinado ambiente e a outra pode desequilibrá-lo totalmente; assim, dificilmente duas mesas seriam idênticas.

Há algumas características comuns a todos esses processos: eles são "impermanentes", nascem, se desenvolvem, amadurecem, decaem e morrem. Eles "não são nada", "estão vazios", no sentido de não terem substância ou essência duradoura que os caracterize ${ }^{7}$. Ou seja, nenhum desses processos é "em-si", sendo, unicamente, "entre-si", pois não podem ser entendidos fora de sua relação e continuidade: se considerarmos uma pedra, ela não é sozinha,

${ }^{4}$ Fluxo contínuo. Descreve o estado em que se encontram todos os processos. Do sânscrito samsara, literalmente "movimento contínuo" ou "fluxo contínuo". Em muitas linguagens indianas modernas significa “mundo físico, universo; família”. Em chinês 輪迴 lún húi: "roda que gira".

${ }^{5}$ Hall e Ames (1995; p. 215): "Processo implica unicidade e faz problemática qualquer noção de identidade estrita" e (p. 233) "Onde um taoista celebra sua unidade com todas as coisas, o significado de "unidade" é "continuidade" com outras coisas, não "identidade".

${ }^{6}$ Impermanência. Refere-se a uma característica comum a todos os processos: eles mudam constantemente, aparecem, crescem, amadurecem, decaem e somem. Do pali: anicca; sânscrito: anitya; chinês: 無 常' wúcháng: "sem constância". A palavra pali anicca significa literalmente "inconstante" e é formada pela partícula negativa " $a$ " e a palavra "nicca", que significa "continuidade e permanência". Essa impermanência se aplica à cadeira onde estou sentado, mas também às rochas, aos oceanos, aos continentes, ao planeta, às estrelas, às galáxias.

${ }^{7}$ Vazio, sem substância ou essência. Aplica-se a todos os processos: eles carecem de substância básica (até a matéria é formada por átomos, que nada mais são do que energia aparentemente "solidificada"). Do sânscrito sunyata: "nada, zero, vazio"; em chinês 空 köng, formado por 穴 xué: "um buraco, uma caverna, um furo" e 工 göng: "esquadro de carpinteiro; por extensão: obra, tarefa, ornamento"; o conjunto 空 representa um "processo vazio, oco" e significa: "vazio, nada; espaço sideral; vão, sem valor". Os átomos de meu corpo originaram-se no interior de estrelas como subproduto do processo que produz sua energia ao fusionar o hidrogênio em hélio (o chamado ciclo do carbono). Esses átomos espalharam-se pelo espaço quando essas estrelas explodiram no final da sua vida e concentraram-se ao redor do Sol quando ele se formou, passando a fazer parte do planeta Terra e, finalmente, chegaram a formar "meu" corpo. Só que, quando o Sol explodir, esses átomos voltarão a se espalhar pelo espaço, independentemente do fato de "eu" ter sido cremado ou sepultado. 
necessitamos da visão ou do tato como agentes intermediários entre elas e nós. Resumindo, em português claro, esses processos "não são, estão sendo" .

Mas, quem somos nós, que observamos esse fluxo de coisas? Nada além de coisas a mais, processos também impermanentes, que se relacionam e interagem com todos os outros processos que acontecem independentemente de nossa vontade. Temos nossas características imanentes, claro, e dentre elas gostamos de destacar o pensamento racional, mas, apesar de nossas mais caras crenças, não somos entidades como pensamos ser, já que também somos vazios, ou seja, somos processos compostos e complexos, sem um "eu" ou uma "alma" com os quais poderíamos nos identificar". Somos processos formados por inúmeros outros processos independentes de um "mim" ou de uma "minha vontade" ("meu" aparato digestivo funciona sozinho e afeta "meu" humor; "meu" sangue circula sozinho; "meus" hormônios se produzem sozinhos nas quantidades necessárias; "minha” respiração se produz sozinha; quando durmo "meus" sonhos chegam sozinhos; "meus" pensamentos invadem, sozinhos, a "minha" mente; "meus" desejos aparecem sem que eu os convoque; "minhas" mãos tremem sozinhas, etc.).

Um ponto que nos custa muito reconhecer é a continuidade que existe entre todos os processos e esse composto que chamamos de "eu". Vejamos o seguinte exemplo, no qual eu digo, ecoando Descartes (Primeira Meditação Metafísica, 1996; p.258):
Estou aqui, sentado junto ao fogo, vestido com um chambre, tendo este papel entre as mãos, e [me pergunto,] como poderia eu negar que estas mãos e este corpo sejam meus?

\footnotetext{
${ }^{8}$ Frase muito difícil de traduzir a línguas que alguns supõem ser mais bem aparelhadas para fazer filosofia do que o português ou o espanhol, como seriam o grego, o alemão, o inglês ou o francês. E por quê? Porque elas não possuem o verbo "estar" no seu sentido de "ter ou apresentar (certa condição física, emocional, material, profissional, etc., não permanente); encontrar-se (em certo momento ou lugar, transitoriamente)". Se considerarmos o inglês, esta frase deve ser traduzida como they are not, they are being, literalmente "eles não são, eles são sendo", o que obriga a destacar implicitamente a existência de um sujeito separado dos outros fenômenos, a perder a referência direta à transitoriedade e a enfatizar o verbo "ser" com suas conotações sobre essências, substâncias, etc. Na filosofia ocidental o primeiro a defender essa transitoriedade no século V a.C. foi Heráclito com seu rio, que nunca era o mesmo, mas foi necessário esperar o século XX para que essa ideia fosse novamente defendida com força. Esta frase pode, às vezes, ser inadequadamente interpretada como "vir-a-ser" (derivada, por exemplo, do inglês they are becoming que tenta fugir da armadilha do verbo to be); mas isso não somente transfere o foco do presente para um momento seguinte que nem sabemos se conseguiremos viver (nesta interpretação fica implícito que "ainda não somos"), como implica uma teleologia, no sentido de existir algo específico que TEMOS que realizar.

${ }^{9}$ Sem-Eu. Do sânscrito anatman, literalmente "não-eu"; em chinês 無我 $w u$ wô: “sem eu, sem meu". Como b é, especificamente, o pronome da primeira pessoa do singular, percebemos que o conceito de anatman não é uma discussão sobre a existência ou não de um $e u$ freudiano, mas de algo mais simples e perturbador: o questionamento da existência de um sujeito para as ações verbais em função de sermos um processo composto.
} 
Nesse momento o latido de um cachorro interrompe meus pensamentos e repentinamente percebo (eu, porque nem Descartes, nem ninguém da sua época, tinha como saber desses mecanismos) que, para que isso tenha ocorrido, "algo" chamou a atenção do cachorro e o motivou a fazer vibrar suas cordas vocais, mexendo com o ar ao seu redor; esta alteração das moléculas do ar se propagou na forma de ondas até atingir meu ouvido; a pressão do ar foi decodificada pelos sensores nervosos auditivos e uma corrente elétrica circulou até meu cérebro onde alterou a profunda observação do meu "eu", na qual me encontrava submerso. Se um cachorro tivesse latido naquele momento próximo de Descartes, possivelmente a história do pensamento ocidental teria sido diferente, visto não podermos definir com clareza onde termina o cachorro e onde começa o "eu" que Descartes entendeu ter identificado. Há uma continuidade entre esses processos que, como já dizia o filósofo taoista chinês Zhuangzi, (século IV a.C., 700 anos antes de o budismo chegar à China) nada mais é do que “物 化 wùhuà, as coisas se transformando" umas nas outras (ZHUANGZI, p.53).

Este processo composto, que por comodidade chamamos erroneamente de "eu", é muito afetado, tanto pela ideia da sua própria impermanência, que comparte com todos os processos, quanto por se relacionar com o todo no qual está imerso, apegando-se a esses outros processos sem aceitar sua transitoriedade. E qual é a causa deste apego?

\section{A nossa relação com os outros processos}

A causa desse apego decorre da forma de funcionar dos sentidos e do pensamento. Trata-se de processos independentes e inter-relacionados, descritos no budismo através do mecanismo dos Doze Elos da Origem Interdependente ${ }^{10} \mathrm{e}$ do qual podemos dizer, de forma breve e um tanto livre, que nosso "estar sendo neste momento ${ }^{11}$ presente", encontra-se condicionado e estruturado:

\footnotetext{
${ }^{10}$ Doze causas (ou Doze Elos da Origem Interdependente). Um mecanismo elaborado (do qual existem variações significativas de escola para escola) que descreve as causas da nossa relação estabanada com os processos que nos rodeiam e representa a Segunda Nobre Verdade de Buda: "Há uma causa para o dukkha”. Do sânscrito pratîtyasamutpâda. chinês: 緣 起 yuánqî: “a causa do que aparece".

${ }^{11}$ Não confundir "momento" com "instante". "Instante" é a "divisão arbitrária e indeterminada de uma entidade transcendental chamada "tempo", que se caracteriza pela sua insensibilidade e pela dificuldade em fazer a diferença entre um instante e outro. Com relação a essa entidade é interessante destacar o comentário de Santo Agostinho (1996, p.322): "O que é o tempo? Se ninguém mo perguntar, o sei; se o quiser explicar a quem me fizer a pergunta, já não sei”. Infelizmente, textos de física moderna sobre o assunto não ajudam muito porque parecem mais arcanos e esotéricos do que tratados hinduístas medievais sobre a metempsicose. Por outro lado, momento é uma "circunstância ou concorrência de circunstâncias; conjuntura, situação", implicando, portanto, na inter-relação entre diferentes processos e caracterizando-se pela sua qualidade e intensidade, o que distingue claramente um momento do outro. Curiosidade: os chineses nunca desenvolveram o conceito de "tempo" e quando tiveram que traduzi-lo ao chinês, no final do século XIX, inventaram o neologismo 時間 shijian, (que passou diretamente ao japonês), que significa, literalmente, “entre momentos" (é inevitável aqui destacar o aspecto "bergsoniano" dessa tradução, que quase podemos chamar de "duração" no sentido utilizado pelo filósofo francês Henry Bergson).
} 
- Pela ignorância, que condiciona os processos. Ignorância é achar que somos algo diferente e separado de todos os outros processos, aos quais atribuímos existências independentes, em lugar de ver-nos como partes interligadas de um todo. Mais ainda, fazemos uma seleção arbitrária das propriedades dos outros processos, fato destacado pela Psicologia Gestáltica como "figura e fundo", e nos limitamos a essa seleção, sem perceber que a mudamos temporalmente: num momento vemos um aspecto, noutro, atentamos para outro, tudo no mesmo processo. A ignorância consiste em reduzir o processo observado àqueles aspectos que selecionamos).

- Pelos processos, que condicionam as atividades "volicionais". Considerar os processos como existências separadas gera em nós impulsos, motivações, vontade de "estar-sendo". Noutras palavras, vemos nos processos aquilo que nossa mente neles projeta, ao invés de nos focarmos em suas propriedades).

- Pelas atividades volicionais, que condicionam a consciência. A forma de operar da nossa mente memória, raciocínio, etc. -, e sua relação com os processos externos, criam em nós a ilusão de sermos um "eu" separado deles).

- Pela consciência, que condiciona o corpo e a mente. Corpo e mente, que são os canais de informação e comunicação com os processos que nos rodeiam. Eles reforçam a ligação entre alguns aspectos dos mundos externo e interno, limitando e filtrando os contatos entre eles, pemitindo, assim, a perda de uma continuidade mais fluida e ampla). - Pelo corpo e pela mente, que condicionam os sentidos. Os orgãos sensores funcionam constantemente: por exemplo, meu ouvido está sempre ouvindo, mas não capta todos os sons, como meus olhos só podem perceber a luz do espectro visível, única a nos fazer reagir no campo da visão).

- Pelos sentidos, que condicionam as sensações. Por exemplo, meu ouvido pode estar ouvindo, mas eu não estou escutando todos os sons ou, ainda, esquecendo a continuidade básica entre os processos que permitem o funcionamento dos sentidos, como no exemplo do cachorro de Descartes, fazemos uma seleção arbitrária daquilo que percebemos. 
Numa linguagem mais “moderna”, estímulos subliminares influem na minha conduta sem "eu" o perceber. Essa seleção origina a fantasia da "objetividade" dos processos externos.

- Pelas sensações, que condiçionam as emoções. Aquilo que escuto ou vejo gera em mim emoções, as quais escondem e englobam todos os passos anteriores, constituíndo-se no motivador principal das nossas condutas. É importante notar que as emoções estão localizadas no processo que chamo de "eu", o que me isola ainda mais dos outros processos, escondendo o efeito básico da "continuidade"). - Pelas emoções, que condicionam os desejos. Gerase o desejo de manter as emoções gratificantes e eliminar as indesejáveis. Aqui, nossas condutas começam a ser claramente visíveis, já que são orientadas para essa satisfação, que é também impermanente, como toda a relação entre os processos).

- Pelos desejos, que condicionam os apegos. Tento manter aquilo de que gosto, isolando-o do resto. Aqui a repetição reina poderosa: faço, reiteradamente, aquilo de que aprendi a gostar e fujo daquilo de que aprendi a desgostar).

- Pelos apegos, que condicionam o "estar sendo neste momento". Estabelecemos uma combinação das causas anteriores numa aparente unidade. Estruturamos nossa ideia sobre nós mesmos e sobre o mundo que nos rodeia, e achamos que descreve adequadamente o conjunto da relação entre eles. Passamos a afirmar: "as coisas são assim”).

- Pelo "estar sendo neste momento", que condiciona este renascimento. A intensidade e a plenitude com que conseguimos viver e nos relacionar com os outros processos neste momento presente fica limitada pelas restrições acima: os filtros dos apegos e dos sentidos, a rigidez das nossas ideias, a transitoriedade que não conseguimos assimilar e a continuidade que não conseguimos perceber).

- Pelo renascimento, que condiciona a decadência e a morte. Trata-se da percepção do inevitável declínio do momento atual e de sua "morte", ou seja, de sua tranformação noutro, no qual nossa combinação de "estarmos sendo" poderia até ser diferente, se conseguíssemos superar a ignorância com que voltamos a começar o novo ciclo). 
O mecanismo dos Doze Elos pode ser expresso da seguinte forma: esse processo emaranhado que "está sendo", e que por comodidade chamo de "eu", interage com os outros fenômenos em função da complexidade de nossa constituição (esta, além de acrescida de nossas incapacidades e frustrações, está sob a influência, ora de uma, ora de outra causa ou mecanismo). Tal interação ocorre de uma forma estabanada ${ }^{12}$ (descentrada, desequilibrada, chacoalhante: constantemente abanando, agitando, batendo, remexendo, sacolejando, sacudindo) o que nos faz, permanentemente, esbarrar - às vezes até com certa violência - nos outros processos, machucando-nos e sofrendo. Essa agitação se origina na nossa ignorância sobre esses outros processos, sobre as características da nossa interação com eles, sobre as limitações das nossas capacidades e sobre nossa dificuldade intrínseca em satisfazer nossos intermináveis desejos de que as coisas tomem um rumo definido.

Esse fluxo de processos chacoalhantes não é realmente composto por coisas, mas por uma sucessão de momentos, cada um deles caracterizado pela quantidade de processos interagentes e pela intensidade com que interagem. Os momentos chegam e vão como a respiração, sendo alguns agitados, como uma respiração of egante, outros intensos e plácidos, como uma respiração profunda.

Mas, se não somos uma entidade, se não temos "eu" nem "alma", se "não somos, só estamos sendo", se estamos intrinsecamente interligados com os processos que interagem conosco, quem é que vive através desses diferentes momentos? O filósofo espanhol Ortega y Gasset disse: "Eu sou eu e minhas circunstâncias" (1966; volume I, p. 322) e, como consequiência, quando essas circunstâncias mudam, ou seja, quando muda o momento, "eu" já não mais sou o mesmo "eu" anterior. Na realidade, somos um processo que faz parte de um momento e, quando esse momento acaba, bem podemos dizer que morremos, só para renascer no momento seguinte (neste sentido, o que sobrou em nós da criança que fomos? como podemos dizer que somos os mesmos? só por possuir um documento que registra os mesmos nomes, sobrenome e filiação? $)^{13}$.

\footnotetext{
${ }^{12}$ Relação estabanada. Refere-se à forma desequilibrada com que nos relacionamos com os processos que nos rodeiam e representa a chamada Primeira Nobre Verdade de Buda: "Tudo é dukkha". Podemos comparar as palavras sânscritas sukha "prazer, conforto, bem-aventurança" com $d u$ hkha "miséria, infelicidade, dor". Su e dus são prefixos, indicando bom ou ruim. Kha, que em sânscrito tardio significa "céu, éter ou espaço", foi originalmente a palavra para "buraco", em particular o furo do eixo da roda de um veículo (os antigos arianos eram nômades que viajavam em veículos puxados por cavalos ou bois). Assim, sukha significava originalmente "ter um bom furo do eixo", enquanto duhkha significava "ter um furo de eixo ruim", levando a desconforto no movimento. Em chinês é referido como 苦 kûu, kû: "amargo". A palavra dukkha é geralmente traduzida por "sofrimento" o que transforma as palavras de Buda em "tudo é sofrimento", contribuindo com a pecha de "pessimista" erroneamente posta no budismo.

${ }^{13}$ Renascimento. Do sânscrito punarbhava, literalmente "voltar a ser"; em chinês 新生 xinsheng: "vida nova". É preferível não utilizar a forma mais comum de "reencarnação" porque leva a inúmeros conflitos com o conceito budista de não-eu (Quem ou o que reencarna? Onde? Quando?).
} 
Outra forma de dizer isto é: "só podemos viver no presente, o passado já foi e o futuro ainda não chegou". Nesse constante renascer nós carregamos as características próprias de um momento para o próximo, de um nascimento para o seguinte, de uma vida para a outra. Então:

- Inspiramos, e o oxigênio se espalha no corpo,
energizando os processos internos. Vivemos.
- Os processos internos consomem esse oxigê-
nio, gerando dióxido de carbono, e ficam sem com-
bustível para continuá-los. Expiramos.
- Esse expirar equivale a morrer, já que se não
voltarmos a inspirar, estaremos efetivamente
mortos. Renascemos.
- Portanto, com cada novo ciclo de inspira-
ção-expiração nascemos, vivemos, morremos
e renascemos.

Assim como só podemos estar seguros do ar entrando nos nossos pulmões na nossa inspiração atual (que será provavelmente seguida por uma expiração, mas que também poderá ser a última), só podemos ter alguma ideia de como estamos iniciando este momento que está chegando, e não de como acabará. Devemos nos esforçar para vivê-lo com intensidade e atenção plenas, a fim de deixá-lo ir quando ele se esgotar, criando, assim, espaço para outro momento: nosso próximo renascimento. Nossa dificuldade para viver os momentos de forma equilibrada faz com que o desequilíbrio se propague, interferindo nos momentos seguintes, ou, podemos dizer, nas vidas seguintes, contaminando-as através do karma ${ }^{14}$, que é a relação existente entre causas e consequências, entre ação e reação. Deste modo, a uma ação equilibrada seguirão consequências agradáveis; a uma ação estabanada, seguirão consequências ruins que conduzirão a desequilíbrios maiores. Mas, visto que somos um processo em permanente interação com os outros, é inevitável realizar ações que provoquem consequências, como se denota, por exemplo, da grande quantidade de mestres budistas que escreveram textos para influir nos seus leitores. Ou, será que deveríamos nos condenar a uma paralisia infrutífera? Não. Karma refere-se especificamente às ações executadas com intenção, porque isso implica numa expectativa do resultado a ser obtido.

\footnotetext{
${ }^{14}$ Conseqüências das ações. Do sânscrito karma “ação". Em chinês 因果 yinguo: “causa e efeito". Nos textos sânscritos budistas este conceito é frequentemente expressado como karma vipaka, lit. "o fruto das ações". Não deve se cometer o erro de equipará-lo ao conceito ocidental de "destino", com o qual não tem nada em comum: uma coisa é atribuir o andamento do mundo a uma entidade transcendental que o predetermina e outra é a constatação pura e simples de que toda ação gera alguma consequência.
} 
E é aí que mora o perigo, já que, em lugar de deixar os fenômenos interagirem livremente, queremos forçá-los a se desenvolverem em uma direção predeterminada que nos parece preferível, por qualquer razão que seja ${ }^{15}$.

De que outra forma é possível entender o karma? Simplesmente como repetição, já que ele equivale ao funcionamento de um piloto automático, continuando a fazer o que estávamos fazendo no ciclo (ou vida) anterior. Como a respiração é automática, pois não requer a nossa atenção, não percebemos a transição, e achamos, assim, que nada de novo aconteceu. Desta forma, com este renascimento não consciente, não somos "novos". Trazemos conosco uma bagagem de influências culturais e familiares, de efeitos da nossa constituição genética, de memórias da nossa história pessoal e do resultado de nossas ações passadas. Tudo isso cristalizado na forma de hábitos.

Não se trata, no entanto, só de repetição de ações, mas, também, de modos de pensar, de mecanismos psicológicos, de idéias, emoções, preferências, entre outras tantas coisas. Gostamos - muito - de nos imaginar livres, mas a realidade é que estamos presos a nós mesmos, aos nossos mecanismos repetitivos, à lei do menor esforço, à inércia, ao não inovar. Infelizmente, é mais fácil deixar-nos levar pelo repetido e conhecido do que experimentar algo novo (sem esquecermos que muitas vezes, e de forma insidiosa, o velho se transveste de novo para nos autoenganar). Todos os nossos condicionamentos e apegos agem contra nós. Nossa fantasia de termos um "eu" constante que se propaga ao longo de inumeráveis ciclos de inspiração-expiração nos grita: "está errado, você é o mesmo!"; "fica no conhecido, não pula no desconhecido!"; "você é assim, goste ou não".

Esta mudança de paradigma não é algo que se possa conseguir da noite para o dia. Temos que desaprender e reaprender muita coisa, então, por onde começar? Será que há forma de sair desta armadilha do tipo "se correr o bicho pega, se ficar o bicho come" e atingir o nirvana ${ }^{16}$, que nada mais é do que deixar de sentir o "mau cheiro" que acreditamos se desprender dos fenômenos por não se comportarem conforme nossas expectativas e desejos? Para isso se desenvolveram as diferentes práticas e se criaram as diferentes escolas budistas,

\footnotetext{
${ }^{15}$ A ideia de deixar interagir livremente todos os processos, com a mesma restrição à interferência intencional por parte dos homens, é o que os chineses chamam 道 Dao (Tao), que pode ser traduzida como o "curso" ou "caminho" natural do processo total que engloba os dez mil processos que formam esse todo. O conceito de Dao remonta aos primórdios do pensamento chinês e foi elaborado em profundidade no Daodejing (Tao Te Ching), obra atribuída a Laozi (Lao Tze, século V a.C.), aproximadamente contemporâneo de Buda.

${ }^{16}$ Nirvana. Palavra sânscrita composta pelo prefixo nir, que significa "para fora, longe, sem", e a raiz $v a[n a]$, que pode ser traduzido como "sopro", "sopro do vento" e também como "cheiro". Pode ser interpretada, então, como "sem cheirar ou feder". Em chinês foi transliterado foneticamente como 涅搫 niepan: lit. “o preto não avança”. O conceito é muitas vezes traduzido como "paraíso", mas isso conduz a uma visão errada que o assimilaria aos paraísos cristão ou islâmico, superlotados de anjos e deuses.
} 
mas, assim como todos os caminhos conduzem a Roma, devemos procurar aquele que mais sentido faz para cada um de nós para, então, percorrê-lo até que a luz se faça na nossa cabeça e o perfume substitua ao fedor. O objetivo da prática é aprender a evitar a contaminação do momento seguinte com as limitações e imperfeições do momento presente, tudo dentro das nossas possibilidades, já que não temos controle sobre o andamento dos fenômenos externos (um asteroide pode estar a caminho da Terra e chocar-se contra ela: o que podemos fazer neste caso?) nem dos internos (células dentro do "meu" corpo podem estar virando um câncer ou micróbios que aspirei podem estar reproduzindo-se e virando uma pneumonia). E por que uma prática? Porque não se trata de "saber sobre", ou seja, de teorizar, mas, sim, de "saber como fazer", ou seja, de agir. Noutras palavras, o nirvana está aqui, no meio do mundo fenomênico e disponível para cada um de nós: é só mudar a forma de enxergar as coisas, vivendo com intensidade e profundidade cada momento e respeitando suas características. Deixando-o vir e deixando-o ir, como fazemos com a respiração. Fazer como dizia Montaigne (1996, Volume II, p.390):

Quando danço, danço; quando durmo, durmo; e mesmo quando passeio por um belo bosque, se porventura meus pensamentos se dirigem para coisas estranhas, forço-os a voltar-se para o bosque [...]

Mas isso nos parece fácil demais e não percebemos a profundidade da mudança requerida.

Quando Buda perguntou a um discípulo: “qual é a duração da vida?” e este respondeu: "um inspirar e um expirar" colocou exatamente o que estamos a dizer. Só estamos sendo no momento presente, o passado se foi e o futuro não chegou. Mas, neste presente, estamos condicionados pelo que fizemos no momento anterior, e isso é o karma: o simples resultado da ação que efetuamos no momento anterior, tenha sido ela boa ou má, branca ou preta. Ao realizar espontaneamente o que é adequado num determinado momento, estamos efetuando uma ação sem karma, porque, no instante seguinte, não nos lembramos dela e não nos preocupamos com o que fizemos ou porque o fizemos, e estamos livres para viver esse novo momento na sua plenitude, incondicionados pelo nosso passado. Desta forma estamos vivendo integralmente no presente, e isso é o nirvana, já que não sentimos dor pelo que já não temos, nem ansiedade pelo que ainda não chegou.

Resumindo mais uma vez: "estamos sendo no momento", "interagindo com os dez-mil-processos que nos rodeiam", e deveríamos fazê-lo de forma "equilibrada e harmônica", prestando "atenção plena à intensidade e à 
qualidade desse momento", no intuito de "evitar chocar-se inutilmente contra esses dez-mil-processos", deixando de "vê-los como algo preto e fedorento" 17 . Para tanto, devemos mudar os pontos de vista de que tanto aprendemos a gostar e com os quais aprendemos a nos identificar.

\section{O atalho do Zen}

$\mathrm{O}$ zazen (meditação própria do budismo Zen, mas que, com variantes, encontra-se também em outras escolas budistas) é uma prática que nos permite desenvolver a nossa capacidade de viver o momento presente, limitando-o, no seu escopo, para ser mais facilmente observado. Praticamos para viver este presente de forma equilibrada e intensa, aprendendo a direcionar nossa atenção, a fim de nos relacionarmos melhor com as circunstâncias e tentarmos modificar as ações automáticas decorrentes do karma. Noutras palavras, no espaço físico-temporal limitado do zazen, podemos aprender a nos relacionar com os processos que se manifestam no momento: ruídos externos, respiração de outro participante, pensamentos que aparecem na nossa mente, nossa própria respiração, as pernas formiguejando, enfim, processos independentes que podem ser observados ao exercermos nossa atenção plena, para, assim, aprendermos a lidar com eles de forma tal que não contaminem o momento presente. Da mesma forma como vamos a uma academia para manter os músculos ativos, vamos a um zendo (sala de meditação) para manter a mente calma; os músculos se beneficiam com o movimento, a mente com a quietude. Mas, assim como ninguém pode exercitar meus músculos por mim, ninguém pode aquietar minha mente, exceto eu.

${ }^{17}$ Numa tradição diferente do budismo, o taoismo diz algo muito parecido quando afirma (Daodejing, Cap. XXIX, tradução de Sproviero, 1997):

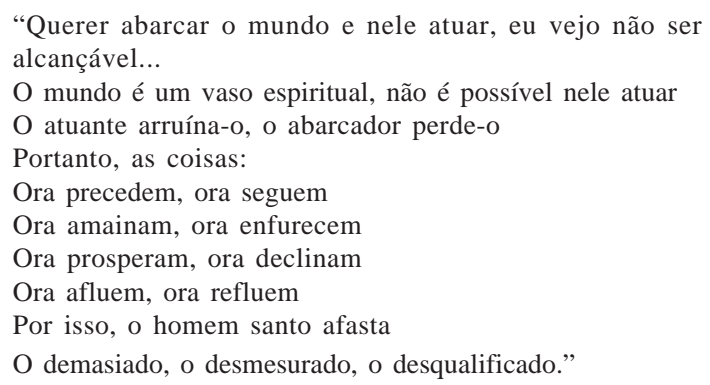

Podemos dizer que o budismo e o taoismo coincidem no diagnóstico sobre nossa relação com os dezmil processos, mas o primeiro, no entanto, elaborou mais profundamente os caminhos que conduzem a uma atitude mais equilibrada e livre perante eles. 
Mas, praticar o que? Praticamos para perceber que cada inspiração é única e diferente da anterior; que não somos obrigados a mudar de posição se o corpo o pedir; que não somos obrigados a continuar uma linha de pensamento que se iniciou numa vida anterior, e que agora não queremos mais; que não somos obrigados a manifestar em ação, ou melhor, em reação, à aparição de um estímulo externo. Praticamos para perceber que a sucessão de ciclos de inspiração-expiração é tão rápida que o nosso perceber não pode se dar numa sucessão de pensamentos, mas deve acontecer numa intuição que se manifeste com a velocidade de um raio ${ }^{18}$. Praticamos para desmontar, aos poucos, a prisão dos hábitos. Praticamos para ter a liberdade de não ter de fazer algo que interfira em nossa escolha do momento: estar sentado meditando. Podemos dizer que a prática da meditação envolve as seguintes características: 1) diminui o dreno de energia centrífuga, orientada aos fenômenos externos, diminuindo, com isso, o estresse, e 2) permite fazer um giro fundamental - em lugar de olhar sempre para fora, nos permitimos a oportunidade de olharmos para dentro, fazendo contato com nós mesmos.

E como se faz? Decido praticar meditação porque "eu quero [...]”, sendo cabível, aqui, qualquer motivação. Sento em posição de lótus, em silêncio e olhando para a parede nua, me concentro na minha respiração, pretendendo esvaziar minha mente de todo pensamento.

O que acontece? Primeiro: a idéia básica do pensamento clássico ocidental, a de um "sujeito" separado de um mundo de "objetos", estoura e fica totalmente insustentável. "Minha" mente, apesar do "eu quero", se mostra totalmente incapaz de se "esvaziar" porque pensamentos pipocam nela, contra "minha vontade". Os ruídos externos, "fora de mim", teimam em desviar "minha" atenção, por mais que "me" concentre. Os músculos das "minhas" pernas tremem sozinhos, apesar de "eu querer" ficar na posição de lótus. Percebo gases se movimentando por "meu" intestino, apesar de "eu" querer ficar quieto. Por mais que pense na tarefa que "eu quero" efetuar não consigo aplicar-me a ela, porque mil e uma coisas interferem. Portanto, imanência e transcendência se esvaem, dentro e fora se confundem, eu e o mundo nos fundimos. Por mais que "queira", não consigo separar-me do mundo. A interação primordial entre o que chamo de "eu" e o que chamo de "mundo" se impõe a todo intento de separar ambos. Percebo que "estou lançado no mundo", como afirmou Heidegger (1989).

Segundo: a epistemologia chacoalha; o que chamamos de "realidade", ou seja, o mundo ao "nosso" redor, deixa de ser uma coleção de "objetos" e se transforma numa rede espaço-temporal de "fenômenos" transitórios que aparecem diante de mim e com os quais tenho que interagir. Um cachorro late na distância,

\footnotetext{
${ }^{18}$ A pesar do alerta que Hume efetuou sobre "as falazes deduções da razão humana, que é lenta em suas operações [...]" (1996, p.71), Ocidente insistiu numa valoração dessa faculdade humana, chegando a divinizá-la nos fins do século XVIII.
} 
"meu" pensamento se desvia e devo "me esforçar" em "me concentrar" novamente. Minha respiração altera seu ritmo e imediatamente compreendo que eu também sou um fenômeno que se apresenta aos meus companheiros de meditação, já que essa "minha" mudança na respiração ou o movimento que não consegui evitar podem distraí-los. Percebo que "eu sou eu e minhas circunstâncias", como disse Ortega y Gasset; mas, (parodiando Richard Rorty, 1997; p. 40), "como sei que sei [sobre minhas circunstâncias] se não sei o que não sei"? Não nos esqueçamos de Descartes e de sua ignorância sobre o mundo ao seu redor, que para nós é quase patética. (Aliás, como será que as gerações futuras considerarão a nossa ignorância presente? $)^{19}$.

Terceiro: o conceito de "tempo" balança. O "eterno", o "constante", o "permanente", se mostram impossíveis. O cachorro late e cala; "minha" mente se acalma, se agita e volta a se acalmar; as montanhas surgem e se aplainam; os continentes se movimentam, as estrelas nascem e explodem. Percebo que "tudo flui como um rio" (frase atribuída a Heráclito de Éfeso, século V a.C.) e que o momento presente é o único concreto entre um passado que é uma lembrança (distorcida porque, inevitavelmente, acaba sendo interpretada a partir do presente) e um futuro que não posso controlar ou predizer (não sei se outro cachorro vai latir ou não, e não sei se estarei aqui para ouvi-lo)

Quarto: a ontologia ocidental titubeia; os conceitos de "ser", "substância" (aquilo que é) e "essência" (aquilo que caracteriza o que é), se esvaziam de conteúdo. Por mais que "pense" não consigo "me" encontrar em lugar algum de forma independente dos fenômenos que me aparecem. Não existem "substâncias" porque todas se unificam nos seus átomos, prótons, quarks, etc., que, em última instância, nada mais são do que formas "solidificadas" de energia. Percebo que "não sou, estou sendo" e me pergunto: por que teria uma "alma" que seria uma exceção a tudo o que observo? Não seria uma forma tola de "querer" ser "eterno", contra todas as evidências?

A meditação permitiu "saber" todas essas coisas? Não. Ela não funciona no nível do "conhecimento", o qual, pelo contrário, é colocado em dúvida.

\footnotetext{
${ }^{19}$ Interessante destacar que, desde a década de 90 (ou seja, ontem, do ponto de vista do desenvolvimento humano), os cientistas reconhecem que só entendem $4 \%$ daquilo que constitui o Universo, a chamada matéria bariônica, que forma todas as galáxias, estrelas e planetas, visíveis ou não. Sobre os $96 \%$ restantes eles não têm a menor ideia do que seja e, por falta de se poder defini-los melhor, são provisoriamente divididos entre as chamadas "energia e matéria escuras". Também na década dos 90 foi detectado o primeiro exoplaneta, ou seja, um planeta girando ao redor de uma estrela que não o Sol e agora já se conhecem mais de 400 deles. Mais recentemente ainda, a revista Science, no seu número de Dez/2010, publicou a descoberta de uma bactéria, a GFAJ-1, num lago da Califórnia, que substitui o fósforo (fundamental para todas as espécies vivas conhecidas até então na Terra) pelo arsênico (venenoso para todas essas espécies). Isso abre perspectivas extraordinárias para pensar a possibilidade de existência de vida em outros planetas, sejam solares ou não. Então, será que sabemos o que é vida? Conhecemos realmente nossas circunstâncias? O que mais não sabemos?
} 
Ela funciona no nível da "experimentação", no contato direto com esses fatos e ideias, contatos que modificam nossa forma de encará-los e nos obrigam a repensá-los. Assim, pouco a pouco poderemos estender essa liberdade aos ciclos de inspiração-expiração que fazemos fora do zazen e, aí sim, começar a viver uma vida liberada dos apegos anteriores, plena de potenciais a serem concretizados. Viver de momento a momento, aqui e agora, com plena atenção e com compreensão das características desse momento e das sementes das situações que estão se gerando ${ }^{20}$. Eis a iluminação!

E o que fazer no caso de nosso ponto de vista conseguir ser mudado? Ah! Como dizia o poeta e contista britânico Rudyard Kipling (1865-1936) no final de cada um de seus contos: "Isso é outra história", e só quem conseguir tal mudança saberá o que fazer quando sentir o perfume, já que a experiência dessa fragrância é incomunicável.

\section{Referências Bibliográficas}

AGOSTINHO, Santo. Confissões. São Paulo: Círculo do Livro, 1996.

CLEARY, T. Las enseñanzas del Zen. Barcelona: Ediciones Oniro, 1998.

DESCARTES, R. Meditaciones metafísicas. Ciudad del Mexico: Editorial Porrúa, 1995.

DESHIMARU, T. La practica del Zen - cuatro textos canônicos Zen. Barcelona: Editorial Kairós, 1985.

DESHIMARU, T. Questions to a Zen master. Nova York: E.P. Dutton, 1985.

DRAGONETTI, C. \& DIGHA NIKAYA. Dialogos mayores de Buda. Caracas: Monte Avila Editores, 1977.

HALL, D.L. \& AMES, R.T. Anticipating China - thinking through the narratives of Chinese and Western culture. Albany: State University of New York Press, 1995.

HEIDEGGER, M. Ser e tempo. Petrópolis: Editora Vozes, 1989.

\footnotetext{
${ }^{20}$ Sementes. Corresponde ao conceito chinês 精 jïng, "essência, espírito, vitalidade; minúcias, detalhes", que já aparece no Daodejing (capítulos XXI e LXIV), e no Xi Ci, o Grande Tratado do século IV a.C., que faz parte integral do Yi Jing (I Ching). Referem-se a que, ao desenvolver a atenção plena, teremos a capacidade de perceber, nos seus primórdios, a possível evolução dos processos que formam nossas circunstâncias, para aceitá-los ou corrigi-los, antes que essa nossa ação se transforme numa violação do andamento natural desses processos, o que caracterizaria uma ação kármica.
} 
HERRIGEL, E. A arte cavalheiresca do arqueiro Zen. São Paulo: Editora Pensamento, 1975.

HERRIGEL, E. The method of Zen. Nova York: Vintage Books e Random House, 1974.

HUI NENG \& TAN JING. Sutra del estrado. Barcelona: Editorial Kairós, 2000.

HUME, D. Investigação acerca do entendimento humano. São Paulo: Círculo do Livro, 1996.

HUMPHREYS, C. Buddhism - An introduction and guide. Londres: Penguin Books, 1985.

HUMPHREYS, C. O Budismo e o caminho da vida. São Paulo: Editora Cultrix, 1976.

IDOETA, I.P. \& ZHUANG ZI. Maestro Chuang Tsé. Barcelona: Editorial Kairós, 1996.

IGARASHI, R.T. Psicologia budista. Rio de Janeiro: Editora Forense, 2002.

IKEDA, D. El budismo chino. Buenos Aires: Emecé Editores, 1993.

JULLIEN, F. Del “tiempo" - Elementos de uma filosofia del vivir. Madrid: Arena Libros, 2001.

JULLIEN, F. Nutrir la vida - Mas alla de la felicidad. Buenos Aires : Katz Editores, 2005.

JULLIEN, F. Procès ou création - Une introduction a la pensee chinoise. Paris : Éditions du Seuil, 1989.

JULLIEN, F. The propensity of things - Toward a history of efficacy in China. Nova York: Zone Books, 1995.

KAPLEAU, P. The three pillars of Zen. Boston: Beacon Press, 1967.

LAO ZI (Lao Tzu). Tao the ching. Texto e comentários de Richard Wilhelm. São Paulo: Editora Pensamento, 1995.

LAO ZI. Escritos do curso e sua virtude (Tao the Ching). Trad. M.B. SPROVIERO. São Paulo: Editora Mandruvá, 1997.

LAO ZI. Libro del curso y de la virtud. Prólogo de F. Jullien. Madrid: Ediciones Siruela, 1998. 
MASUNAGA, R. A primer of Soto Zen. Honolulu: University of Hawaii Press, 1988.

MONTAIGNE, M. Ensaios. São Paulo: Círculo do Livro, 1996.

ORTEGA Y GASSET, J. Obras completas. Madrid: Revista de Occidente, 1966.

PADMA SAMTEM, Lama. A jóia dos desejos. Taquara, RS: Editora Paramita, 1995.

PADMA SAMTEM, Lama. A roda da vida como caminho para a lucidez. São Paulo: Editora Petrópolis, 2010.

QUILES, I. S.J. Filosofia Budista. Buenos Aires: Editorial Troquel, 1973.

RORTY, R. Esperanza o conocimiento? Una introducción al pragmatismo. Buenos Aires: Fondo de Cultura Económica, 1997.

SILVA, G. da \& HOMENKO, R. Budismo: Psicologia do autoconhecimento. São Paulo: Editora Pensamento, sem data.

SPROVIERO, M.B. Escritos do curso e sua virtude (Tao Te Ching). São Paulo: Editora Mandruvá, 1997.

SUZUKI, D.T. \& FROMM, E. Budismo Zen y psicoanalisis. Ciudad del Mexico: Fondo de Cultura Económica, 1964.

SUZUKI, D.T. Introducción al Budismo Zen. Buenos Aires: Editorial Kier, 1976.

SUZUKI, D.T. Manual de Budismo Zen. Buenos Aires: Editorial Kier, 1974.

THICH NHAT HANH. A essência dos ensinamentos de Buda. Rio de Janeiro: Editora Rocco, 2001.

THICH NHAT HANH. The heart of understanding - Commentaries on the Prajnaparamita Hearth Sutra. Berkeley: Parallax Press, 1988.

THICH THIEN-AN. Zen philosophy, Zen practice. Berkeley: Dharma Publishing, 1975.

WILHELM, R. I Ching, o livro das mutações. São Paulo: Pensamento, 1956. 